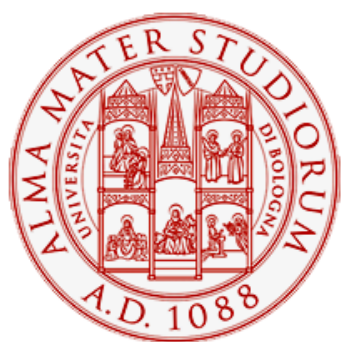

Alma Mater Studiorum - Università di Bologna DEPARTMENT OF ECONOMICS

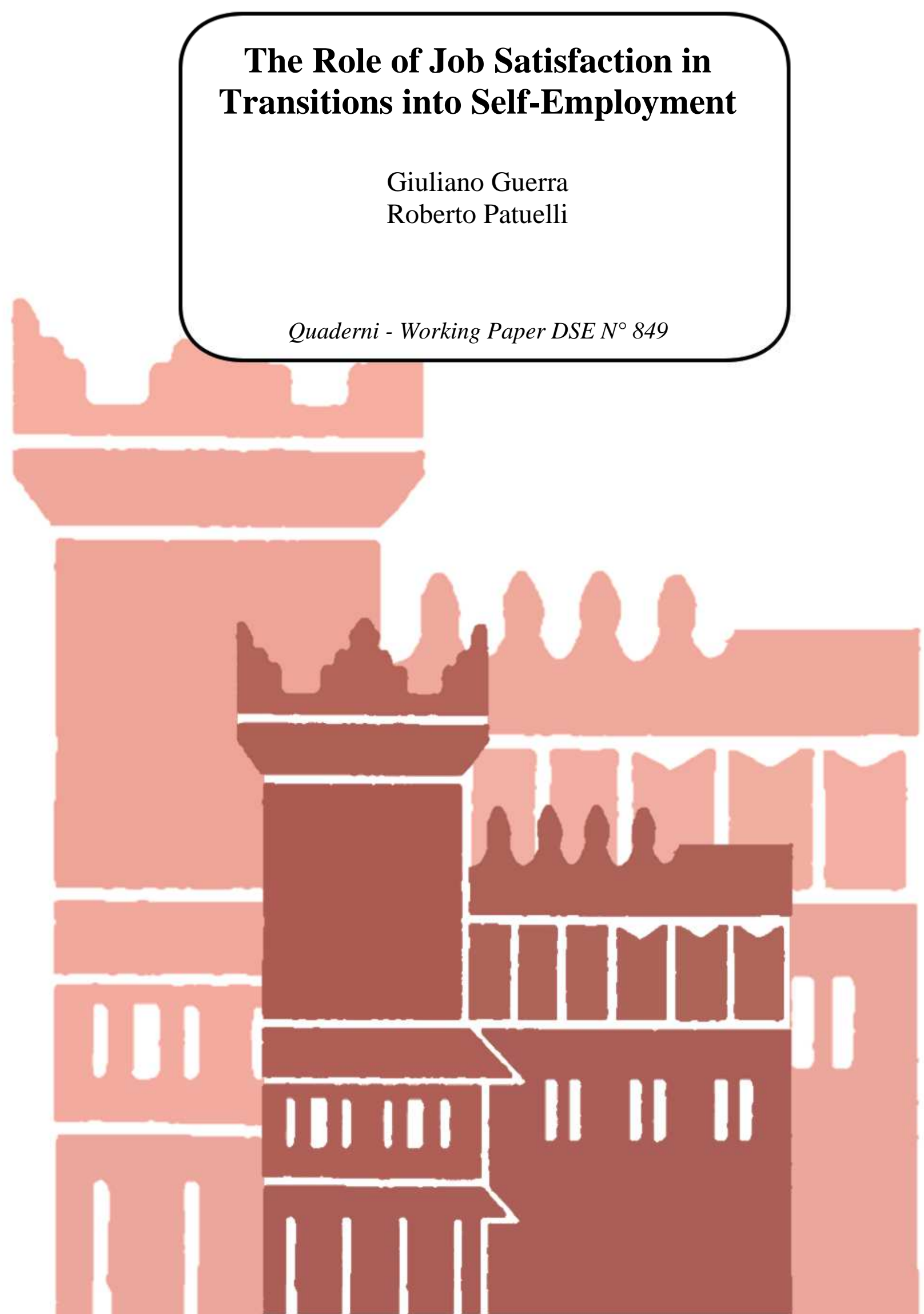




\title{
The Role of Job Satisfaction in Transitions into Self-Employment
}

\author{
Giuliano Guerra \\ Ufficio per lo sviluppo economico, Repubblica e Cantone Ticino, Switzerland \\ Roberto Patuelli \\ Department of Economics, University of Bologna, Italy \\ The Rimini Centre for Economic Analysis (RCEA), Italy
}

This version: 13/09/2012.

\begin{abstract}
As observed in many advanced economies experiencing an increase of self-employment rates since the late 1970s, a flourishing small- and medium-size enterprise sector is traditionally associated with positive economic development and growth. In the regional context, areas benefiting from an established entrepreneurial culture are in general more successful and innovative, as well as better equipped to sustain structural changes and to lessen unemployment. It is therefore important to investigate the reasons why individuals choose self-employment, and why they do it despite lower protection, higher risks, and possibly more effort than what is required in a comparable wage employment position. Existing research identifies better prospects of entrepreneurial earnings as compared to wages as a major stimulus towards selfemployment. However, besides pecuniary motivations, other factors may be considered when it comes to the occupational choice. These include displacement, uncertainty, (the threat of) unemployment, and (dis)satisfaction. Building on a job quits model, we propose a representation of transition behaviour from wage to self-employment which includes subjective evaluations of pecuniary and nonpecuniary satisfaction on the previous job. Individual microdata are drawn from the Swiss Household Panel (SHP), and cover the time period 1999-2008. Additionally, we focus on the dynamics of job satisfaction in order to highlight the role played by shocks in subjective evaluations, and introduce their interaction with levels to control for threshold effects.
\end{abstract}

Keywords: self-employment, job satisfaction, job transition, Switzerland

JEL codes: C25, J62, M13 


\section{Introduction}

About 650,000 men and women operate as self-employed agents in Switzerland, including incorporated selfemployed (i.e., employed by their own company) and family workers (FSO, 2011a). Comprising almost 15 per cent of all economically active individuals, they run businesses in the retail, trade, manufacturing, financial and insurance sectors, as well as in accommodation and food services (FSO, 2000, 2011a). With a slight delay with respect to other OECD countries, Switzerland has experienced a rise in self-employment rates since the early 1980s (Falter, 2001; Flückiger and Ferro-Luzzi, 2001). Among the factors that may have encouraged this increase in the number of self-employed workers, it is worth mentioning the development of the ICT sector, the improvement in production processes and the increase in outsourcing activities, as well as fiscal and personal reasons (Birchmeier, 2000). In the meanwhile, wage employment may have been affected by rigidities in wages and by the extension of mandatory health insurance to elderly people (Falter et al., 1998). Earnings differentials between self-employed and dependent workers still play in favour of the latter, who earn about 10 per cent more (FSO, 2011a). ${ }^{1}$ However, the share of individuals in the highest-earning class (more than CHF104,000 per year) is considerably larger among the self-employed than among the employees (23 and 18 per cent, respectively, of those reporting positive earnings; FSO, 2011b). Further evidence shows that differences in earnings between self- and wage employment becomes less important for men (6.7 per cent), and indistinguishable for resident immigrants.

Several studies have shed light on the role played by small-business owners in economic growth (e.g., Lucas, 1978; Kihlstrom and Laffont, 1979; Blau, 1985; Brock et al., 1986; Rees and Shah, 1986; Evans and Leighton, 1989; Goetz et al., 2012), and on their ability to create new jobs (Birch, 1979). Existing studies on transitions from wage- to self-employment identify start-ups as an important source of business dynamics and innovation (Jovanovic, 1982; Dunne et al., 1987; Evans, 1987a, 1987b; Pakes and Ericson, 1998). Moreover, differences in the earnings distributions of self-employed workers and dependent employees have been analysed widely, giving rise to a number of theories seeking to explain them (Rosen, 1981; Jovanovic, 1982; Lazear and Moore, 1984).

At the same time, many policy interventions aiming to encourage self-employment have been implemented by national and regional governments in order to stimulate new employment opportunities and reduce unemployment (Blanchflower, 2000). Most governments offer assistance to small businesses, providing subsidies for individual start-ups, and Swiss national and regional policies are no exception. Universities often contribute as well, establishing start-up centres and incubators, with the dual aim of supporting newlyformed businesses and conducting related research. From a regional development perspective, filling up the gap between wage and self-employment earnings may contribute to the convergence of less dynamic and peripheral areas towards more successful and innovative regions (Reynolds, 1994; Reynolds, 1999; Acs and Armington, 2004).

Existing research on self-employment transitions makes a wide use of rational agent-based models assuming that individuals choose self-employment if the expected utility of this option exceeds the one associated with wage employment. Better prospects of entrepreneurial earnings as compared to wages are, according to the greater part of this literature, a major stimulus towards self-employment (Rees and Shah, 1986; Fujii and Hawley, 1991; Taylor, 1996).

However, besides pecuniary motivations, other factors come into consideration when it comes to occupational choice. Recently, the assumption that earnings act as a proxy for utility has been relaxed. Hamilton (2000) shows that the nonpecuniary benefits of self-employment are substantial, with most entrepreneurs entering - and staying in - business despite lower initial earnings and lower earnings growth

\footnotetext{
${ }^{1}$ Computations are made on full-time yearly gross revenues evaluated at the median for resident dependent workers $($ CHF80,400) against self-employed and family workers $($ CHF72,900) for the year 2009.
} 
with respect to wage employment. Evans and Leighton (1990) and Taylor (1996) find that, besides higher expected earnings, the independence offered by self-employment positively influences individual decisions towards business ownership.

A nonpecuniary aspect which is often advocated as a major driving force in entrepreneurship is the one associated with (dis-)satisfaction. Brockhaus (1982) finds self-employed workers to be relatively strongly dissatisfied with their previous (dependent) work, supervision and career opportunities, even if this such ex post assessments could be influenced by the opportunities offered in the new position. More generally, emotional factors such as feeling inappropriate/displaced and uncertainty often precede the formation of a company (Shapero and Sokol, 1982). Indeed, at the macro level, countries with lower rates of dissatisfaction with life and society in general have been shown to experience higher self-employment rates (Noorderhaven et al., 2004). Moreover, (the threat of) unemployment, as well as being bored or angered, has been shown to positively affect self-employment choices (Wennekers et al., 2001; Hofstede et al., 2004). Thus, individuals dissatisfied with their job may be expected to be more inclined to enter self-employment. As a result, selfemployed individuals generally report higher satisfaction with their job than employees (Blanchflower and Freeman, 1997; Blanchflower and Oswald, 1998; Blanchflower, 2000; Taylor, 2004). However, the literature is limited on the subjective characteristics of wage employment that are expected to lead to entrepreneurship, as well as on the dynamics of job satisfaction.

Since individuals may self-select into entrepreneurship (given the inability to find a satisfying job in the case of low-skilled workers, or the inexistence of comparatively remunerated alternatives in wage employment in the case, for example, of physicians or lawyers), it is important to look also at objective working conditions, so that job satisfaction can be seen as an "excess" reward discounting future potential flows of utility deriving from a change in working conditions with respect to the current situation. Moreover, given the (relatively) high persistence of job satisfaction levels and the reduced propensity to react to them with longer tenure (and greater age), we propose to look not only at the level of job satisfaction, but also at its variation. Dissatisfied workers may react to recent improvements in job satisfaction differently from more satisfied workers.

Building on a job quits model (Freeman, 1978; McEvoy and Cascio, 1985; Akerlof et al., 1988), we propose a representation of transition behaviour from wage to self-employment which includes (previous) subjective evaluations of job satisfaction. Individual microdata are drawn from the Swiss Household Panel (SHP) and cover the time period 1999-2008. We use two measures of job satisfaction, satisfaction with income and satisfaction with working conditions, and we regard them as direct measures of individuals utility (Clark and Oswald, 1996; Taylor, 2004). Rather than including current levels of satisfaction or assessments regarding past work characteristics, we rely on subjective levels of satisfaction that were reported before the choice was made, so as to measure real/actual perceptions about past working conditions.

Additionally, we focus on the dynamics of job satisfaction in order to highlight the role played by shocks in subjective evaluations and introduce their interaction with levels to control for threshold effects. Unlike most of the studies cited above, we are able to discriminate between the evaluations regarding pecuniary and nonpecuniary benefits, and to address the question of whether the inclusion of subjective variables and their variations in time matter in modelling self-employment transitions and job quits.

The remainder of the paper is structured as follows. In Section 2 we discuss our empirical approach. In Section 3 we briefly describe the data. In Section 4 we present estimates for our model of job transitions. In Section 5 we summarize and discuss our findings. 


\section{The Model}

Despite the widespread use of job satisfaction measures in the social sciences, economists have often been reluctant to incorporate such variables in their models, partly because of their subjective nature, and partly because satisfaction is supposed to provide a proxy for individual utility, and thus it requires caution (Freeman, 1978).

A promising representation of the choice problem faced by individuals addressing the question of whether or not leaving a paid position for venturing into self-employment is the one provided by the job quits literature (Flanagan et al., 1974; Freeman, 1978; McEvoy and Cascio, 1985; Akerlof et al., 1988; Clark et al., 1999). Within this framework, it is assumed that individuals consider the opportunity of voluntarily leaving their job as a function of their expectations regarding pecuniary and nonpecuniary benefits outside of the current employer compared to those offered inside, in addition to mobility costs (Lévy-Garboua et al., 2007). Job quits are observed among individuals reporting a positive difference between the sums of pecuniary and nonpecuniary benefits and costs of current and future positions, where job satisfaction is a monotonic, discrete function of these sums (Akerlof et al., 1988). Dissatisfied workers have higher quit rates than satisfied workers because the former perceive the expected present value of their job as being lower with respect to the one offered by outside opportunities. Alternatively, mobile workers experience greater increases in satisfaction if they were willing to leave than if they were not (Bartel and Borjas, 1981; Gottschalk and Maloney, 1985; Clark, 2001). As a result, quitters report higher satisfaction levels in their new job than in their old one (Akerlof et al., 1988).

Similarly, we argue that transitions to self-employment are taken into consideration if the expected pecuniary and nonpecuniary (net) benefits of entrepreneurship are greater than those in paid work. However, since individuals do not have complete and adequate information on these potential benefits before entering selfemployment, they estimate them on the basis on their experience, their level of education and existing opportunities. Job satisfaction can then be seen as a reasonable indicator summing up perceptions about the comparative advantage of remaining in the current job against the alternatives.

However, given the existence of self-selection problems in models explaining entrepreneurial choices optimistic individuals may choose to enter self-employment or simply to evaluate differently the costs that the more heterodox option of turning to self-employment implies (in terms of mobility, and risks) - we include controls for objective job characteristics, so as to regard job satisfaction as the "excess" reward in the current paid job with respect to average rewards potentially available to the worker in self-employment.

Additionally, we include the effects of changes in job satisfaction. Variations in this variable might hide serious concerns about the current and future job position in comparison to past experience. Moreover, since it is likely that workers, while assessing their satisfaction, also include general assessments regarding the alternatives, changes in job satisfaction may reveal the opening of new opportunities against which the comparison is made, or improvements in the existing alternatives.

In order to facilitate comparison with the existing literature on job quits, and to investigate whether job satisfaction affects quits and self-employment transitions differently (as we might expect, since the former decision might be more conservative and less risky), we consider also those who quit their job but remain in paid employment.

For a cross-section of individuals reporting a working status as employee at time $t-1$ and $t-2$, we estimate the effects of (dis-)satisfaction and other determinants on transition probabilities by means of a multinomial logit model (McFadden, 1974; Greene, 2007) taking the form: 


$$
\operatorname{Pr}\left(y_{t}=i\right)=\frac{e^{X_{t-1, t-2} \beta^{(i)}}}{\sum_{i} e^{X_{t-1, t-2} \beta^{(i)}}}
$$

where $i=1,2, \ldots, I$ are the possible outcomes of the transition function $y$, evaluated at time $t$, and $X$ are the explanatory variables evaluated at time $t-1$ and $t-2$. In our model, we assume that there are $I=3$ outcomes: "staying in the current (paid) job", "changing job/employer", and "changing status from wage- to self-employed". We thus estimate two sets of coefficients, $\beta^{(2)}$ and $\beta^{(3)}$, corresponding to the second and third outcomes, respectively, where $\beta^{(1)}$ is set to zero for identification purposes. $\operatorname{Pr}\left(y_{t}=i\right)$ is the probability that the worker will choose the outcome $i$ at time $t$. Probabilities of transition are linked to the individual and job characteristics, including job satisfaction levels evaluated at time $t-2$ and recent variations in job satisfaction. ${ }^{2}$ The matrix of covariates $X$ includes standard socioeconomic variables evaluated at time $t-1$, such as age, gender, nationality, marital status, and the level of education. Additionally, we control for union membership and homeownership. Job characteristics are included as well, and they account for the level of earnings, the number of working hours, and self-assessments regarding job insecurity and unemployment risk. Time fixed effects, controlling for the influence of the business cycle on transition decisions, are incorporated in the model as well.

Job satisfaction is evaluated on a $0-10$ scale, where 0 corresponds to the answer "not at all satisfied" and 10 is "completely satisfied". Dynamic effects of satisfaction on transition probabilities are accounted for through the inclusion of the percentage change between the individual's satisfaction level at time $t-1$ and the level of satisfaction expressed in the year before, divided by the latter:

$$
\frac{\Delta x_{t-1}}{x_{t-2}}=\frac{x_{t-1}-x_{t-2}}{x_{t-2}} .
$$

Since we may expect the dynamics of satisfaction to influence transition probabilities differently depending on the starting level of satisfaction, we include in a second model specification the interaction term between the percentage change and the level of satisfaction. By doing so, we are able to assess whether individuals starting from low levels of satisfaction and experiencing a decline of the same are affected to a greater or smaller extent in their decisions than individuals facing the same percentage change but starting from higher levels of satisfaction. In this respect, our paper intends to fill a gap in turnover research, by including an assessment on the formation of individual perceptions about job satisfaction.

In addition to satisfaction measures, we control for objective job characteristics. The log of the wage is used as a measure of pecuniary rewards, while in order to control for nonpecuniary aspects, we include variables measuring the number of weekly worked hours, the feeling of job insecurity (ranged 1-5), and the risk of falling into unemployment (on a 0-10 scale). A set of additional variables is used to control for differences in human and financial capital: the level of education (distinguishing between individuals with a vocational or a university degree against the reference of those with basic education), union membership, and homeownership. Previous studies have shown that both self-employment probabilities and earnings are strongly influenced by liquidity constraints (Evans and Jovanovic, 1989; Holtz-Eakin et al., 1994; Black et al., 1996; Lindh and Ohlsson, 1996; Blanchflower and Oswald, 1998). Moreover, financial capital, and in particular real estate, is an important source of collateral for entrepreneurs, which is expected to reduce the default premia (Henley, 2005). ${ }^{3}$

\footnotetext{
${ }^{2}$ We select satisfaction levels at time $t-2$ in order to interpret them, in our model specification, as initial levels, while variations in job satisfaction measure changes from the satisfaction level evaluated at time $t-2$ to the level in $t-1$.

${ }^{3}$ It would be worth to address parental background as well, and more specifically the example (familiar role models) provided by the parents, which has been shown to represent a powerful predictor of the propensity towards business
} 
Furthermore, we control for age (which is expected to capture both work experience and wealth accumulation possibilities), nationality, marital status, and gender. Some of these characteristics are expected to capture differences in individual perceptions of, and attitudes to, risk (risk aversion), since individuals may be differently aware of the risk of failure in entrepreneurship or of unemployment in paid work.

\section{Data}

Our empirical analysis makes use of waves 1-10 of the SHP, for the time period 1999-2008. We select men and women above age 18 in the first wave and under age 65 in the last wave, obtaining a sample of over 38,000 observations regarding economically active and inactive individuals who are tracked during the ten years of the survey.

Transitions between four possible employment status categories across all panel waves are summarized in Table 1. As it can be seen from it, the majority of the individuals in wage employment stay in that category from one year to another (more than 92 per cent). Only a small proportion of employees at any time turn to self-employment in the following year (1.9 per cent). Nearly 4 per cent quit wage employment and exit the labour force, and very few become unemployed (1.2 per cent). Among those who were self-employed at $t-$ 1, more than 78 per cent remain self-employed in the following year, whereas a considerable minority transits into wage employment (15.7 per cent) or exit the labour force (5.1 per cent), suggesting that, on average, the self-employed are older than wage employees. In general, self-employment is less stable than wage employment, although transition rates into unemployment and inactivity do not differ much for these two categories. Finally, among those who were unemployed in year $t-1$, the most frequent occurrence is to become either employed or inactive (54.9 and 19.7 per cent respectively) or to remain in unemployment ( 22.8 per cent). Few individuals enter self-employment ( 2.6 per cent), although this probability is higher than for those in wage employment. Among those recorded as inactive, the majority remains inactive in the following year (76.4 per cent) or enters wage employment (18.1 per cent). Transitions into self-employment or unemployment are again rare.

Table 1: Transitions between employment categories

\begin{tabular}{lcccrr}
\hline & Year $t$ & & & \\
\cline { 2 - 6 } Year $t-1$ & Employed & Self-employed & Unemployed & Inactive & \multicolumn{1}{c}{ Total cases } \\
\hline Employed & $25,419(92.6)$ & $511(1.9)$ & $316(1.2)$ & $1,207(4.4)$ & $27,453(100.0)$ \\
Self-employed & $524(15.7)$ & $2,626(78.6)$ & $19(0.6)$ & $171(5.1)$ & $3,340(100.0)$ \\
Unemployed & $387(54.9)$ & $18(2.6)$ & $161(22.8)$ & $139(19.7)$ & $705(100.0)$ \\
Inactive & $1,208(18.1)$ & $192(2.9)$ & $173(2.6)$ & $5,105(76.4)$ & $6,678(100.0)$ \\
Total cases & $27,538(72.1)$ & $3,347(8.8)$ & $669(1.8)$ & $6,622(17.3)$ & $38,176(100.0)$ \\
\hline
\end{tabular}

Note: Transition probabilities between brackets.

In order to analyse transitions from wage- to self-employment, we restrict the data to only the cases in which individuals were employed at times $t-1$ and $t-2$ and either (1) stayed in wage employment without changing their job/employer, (2) quit their job/employer without changing status or (3) became self-

ownership. Although our data set would allow to control for parental occupation, unfortunately the number of cases recorded is too small to provide significant insights. 
employed at time $t$. The information is drawn from the pooled sample of observations from 2001 (Wave 3) to 2008 (Wave 10), which has been further restricted in order to select cases where information on all the listed covariates was available. This confines our analysis to a sample of 4,713 individuals among which 3,004 stay in the previous job (63.7 per cent), 1,266 quit their job/employer (26.9 per cent) and 443 (9.4 per cent) were found to enter self-employment at some time. ${ }^{4}$

In order to investigate the drivers of transitions we consider the variables listed in Table 2. They account for the level of satisfaction regarding pecuniary and nonpecuniary job aspects, human and financial endowments, as well as for other demographic and job characteristics. Table 2 provides separate descriptive statistics for the samples of the stayers, the quitters (who later left their job without changing their status of employees) and the emergent entrepreneurs (who later changed their status to self-employed).

Table 2 - Descriptive Statistics, by Groups (Stayers vs Quitters vs Emergent entrepreneurs)

\begin{tabular}{lllllll}
\hline & Stayers & \multicolumn{3}{c}{ Quitters } & \multicolumn{2}{c}{ Emergent entrepreneurs } \\
& Mean & S.D. & Mean & S.D. & Mean & S.D. \\
\hline Satisfaction & & & & & & \\
$\quad$ Satisfaction: income $(t-2)$ & 7.313 & 1.990 & 6.863 & 2.181 & 6.966 & 2.231 \\
$\quad \%$ change in satisfaction: income & 0.025 & 0.384 & 0.053 & 0.615 & 0.048 & 0.490 \\
$\quad$ Satisfaction: job conditions $(t-2)$ & 7.933 & 1.679 & 7.516 & 1.839 & 8.240 & 1.638 \\
$\quad$ \% change in satisfaction: job conditions & 0.015 & 0.257 & -0.002 & 0.337 & 0.042 & 0.371 \\
Demographics & & & & & & \\
Age & 43.762 & 11.176 & 36.245 & 11.013 & 45.489 & 10.198 \\
Female & 0.494 & 0.500 & 0.475 & 0.500 & 0.549 & 0.498 \\
Ethnic minority & 0.111 & 0.314 & 0.112 & 0.315 & 0.081 & 0.273 \\
Married: no & 0.357 & 0.479 & 0.538 & 0.499 & 0.248 & 0.432 \\
Human and financial capital & & & & & & \\
Education 2 & 0.138 & 0.345 & 0.164 & 0.371 & 0.200 & 0.400 \\
Education 3 & 0.135 & 0.342 & 0.166 & 0.372 & 0.208 & 0.406 \\
$\quad$ Union membership: yes & 0.237 & 0.426 & 0.185 & 0.389 & 0.156 & 0.364 \\
$\quad$ Homeownership & 0.514 & 0.500 & 0.441 & 0.497 & 0.644 & 0.479 \\
Objective work characteristics & & & & & & \\
$\quad$ Income (CHF/1,000) & 62.385 & 43.179 & 56.057 & 58.353 & 72.243 & 99.962 \\
$\quad$ Working hours & 31.269 & 12.011 & 32.815 & 11.366 & 32.571 & 15.321 \\
Job (in-)security & 1.720 & 0.721 & 1.982 & 0.965 & 1.809 & 0.848 \\
Risk of unemployment & 1.624 & 2.224 & 2.835 & 3.017 & 1.679 & 2.599 \\
Cases & 3,004 & & 1,266 & & 443 & \\
\hline
\end{tabular}

The level of satisfaction with income in the sample of quitters and in the one of emergent entrepreneurs is on average lower than the one of the stayers $(6.9,7.0$ and 7.3, respectively), suggesting that dissatisfaction linked to pecuniary aspects may act as a push factor. On the other hand, although percentage changes in income satisfaction are slightly higher among the former two groups than in the control group of the stayers (5.3 and 4.8 , versus 2.5 per cent), all values are very close to zero and heterogeneity is high.

\footnotetext{
${ }^{4}$ This data set restriction is carried out under the assumption that transitions into self-employment are still traceable after one year, that is, that the number of transitions failing before being recorded in the subsequent SHP wave is negligible.
} 
The level of satisfaction with working conditions is on average higher among the emergent entrepreneurs than in the reference group of stayers (8.2 and 8.0, respectively), while the quitters are the least satisfied (7.5). This evidence suggests that the emergent entrepreneurs benefit from more advantageous job conditions or they assess them in a more optimistic way than the ones deciding to stay in wage employment (either changing their job/employer or not). Variations in job satisfaction regarding nonpecuniary aspects are also higher among the group of those that turn to self-employment than among individuals deciding to stay in wage employment, either changing their job or not $(4.2,-0.0$ and 1.5 per cent respectively), but again average variations are small and heterogeneity is high.

In general, in all samples there is less heterogeneity for assessments regarding the level of satisfaction with working conditions than with income. Moreover, in all samples the percentage change in income satisfaction is on average higher than the one in nonpecuniary satisfaction, which may indicate that improvements in the perceptions regarding pecuniary job aspects are more likely to occur (consistently with the underlying distribution of income, that is expected to be more linear in time), even if the high heterogeneity observed suggests that there are many winners and losers.

The average age in the emergent entrepreneurs sample is 45.5 , which is significantly higher than the average age of 43.8 in the stayers sample. ${ }^{5}$ Quitters are on average much younger (36.2). Emergent entrepreneurs are more likely to be female than the stayers and quitters (54.9 per cent, compared to 49.4 and 47.5 per cent, respectively). At a first glance, this suggests that women in Switzerland are more entrepreneurial or that they self-select in sectors characterized by more favourable business opportunities (e.g., personal services, education, health and childcare). The emergent entrepreneurs sample has a significantly lower proportion of foreigners than the other samples, which reflects a peculiarity of the Swiss labour market, where immigrants are less likely than natives to become entrepreneurs (Guerra et al., 2012). The percentage of non-married individuals (single, divorced or widow) is considerably higher among the quitters ( 53.8 per cent) than among the stayers and the emergent entrepreneurs (35.7 and 24.8 per cent).

With regard to the proxies for human and financial endowments, self-employment candidates seem to be more likely to have attained a vocational ( 20.0 per cent) or university degree ( 20.8 per cent) than those staying in wage employment (16.4 and 16.6 per cent among the quitters; 13.8 and 13.5 per cent among the stayers). There are significant differences between the shares of those who are members of a union in the three groups (23.7 per cent among the stayers, 18.5 among the quitters and only 15.6 among the emergent entrepreneurs). Homeownership rates are higher among the emergent entrepreneurs than among the stayers and the quitters (64.4 per cent, against 51.4 and 44.1 per cent, respectively). This preliminary evidence suggests that the probability of transition towards self-employment is associated positively with the level and quality of both human and financial capital, and negatively with union membership, this latter result possibly being related to the different work functions of individuals belonging to the two groups.

Emergent entrepreneurs earn slightly more $(\mathrm{CHF} 9,860$ more per year, +15.8 per cent) than the average stayer, while quitters report on average significantly lower earnings (CHF6,330 less per year, -10.1 per cent). Differences among the three averages are significant at the 1 per cent level. However, heterogeneity in the emergent entrepreneurs sample is particularly high, which suggests that turning to self-employment is not always profitable per se. ${ }^{6}$ There are little, although significant, differences between the working hours reported in the three samples, with a higher number of hours dedicated by the quitters and the emergent entrepreneurs to their working activity. Similarly, differences between those deciding to stay in the current job, the quitters and those turning to self-employment can be found with regard to the level of job insecurity,

\footnotetext{
${ }^{5}$ We test differences by means of a t-test on the null hypothesis that the means in each group (job stayers vs job quitters) are the same. Statistics are not reported, but can be obtained upon request.

${ }^{6}$ In fact, the median income among the stayers (CHF58,310) is higher than for the quitters (CHF50,200) and the emergent entrepreneurs (CHF49,250), which is consistent with FSO data (FSO, 2011a).
} 
with an average level of 1.7, 2.0 and 1.8 respectively. Finally, there is little exposure to unemployment risk in both the stayers and the emergent entrepreneurs samples (1.6 and 1.7, respectively), while the quitters are significantly more exposed (2.8).

We abstain from considering the industrial and professional composition of our sample, since the inclusion of these characteristics was found to capture objective work conditions, without increasing goodness of fit. Furthermore, the high number of missing values for these variables would considerably reduce our sample size. Similarly, the inclusion of regional dummies was found not to affect our results.

\section{Empirical Results}

Our multinomial logit model, consistently with Equation (1), is estimated by maximum likelihood using the covariates discussed in Section 3, and using the subsample of the stayers as the reference category. Table 3 reports a first set of estimates: column (2) shows the vector of regression coefficients and standard errors for the quitters, while column (3) reports estimation results for the emergent entrepreneurs.

The inclusion of satisfaction variables improves the goodness of fit (with respect to a base model including only objective job and personal characteristics, not shown), without affecting sign and significance of other coefficient estimates (McFadden's pseudo- $R^{2}$ of 0.167 against 0.156 in the base model; AIC 6,238.03 against 6,405.62; BIC 6,543.63 against 6,660.90 in the base model). A $\chi^{2}$-based likelihood ratio (LR) test confirms that the inclusion of subjective variables leads to a highly significant model improvement.

According to our results, job satisfaction significantly affects transition probabilities, although its effects are different for job quitters and emergent entrepreneurs. On the one hand, the level of satisfaction regarding pecuniary job rewards (i.e., income) negatively affects the probability of entering self-employment, whereas the effect on the chances of changing job is not statistically significant. Thus, income dissatisfaction represents a push factor for entrepreneurial choices, while it does not affect job quits. With regard to the effect of variations in income satisfaction (our measure of changes in long-run satisfaction levels), recent improvements discourage decisions towards self-employment but increase the probability associated with job quits. On the other hand, the level of satisfaction about nonpecuniary job aspects (i.e., work conditions) negatively influences job quits, but positively affects the probability of moving towards self-employment. These results are reinforced by the effects of the same sign found for the variation variable.

We argue that individual perceptions regarding pecuniary and nonpecuniary job rewards do matter when deciding to take the risk of quitting an existing job for a new career (possibly in self-employment). According to our results, job quitters do not change for money but to improve their working conditions (e.g., to get away from annoying colleagues/boss or to get a more satisfying job), whereas emergent entrepreneurs are generally more satisfied with their work conditions (most likely because of different job functions) but change mostly in hopes of increasing their income.

The opposite signs found for the effects of our two measures of job satisfaction on transition probabilities towards self-employment may reflect differences in the workers' reactions between subjective evaluations of pecuniary and nonpecuniary aspects. Such differences may arise because of the different nature and distribution of the underlying work characteristics (income and job conditions, respectively). Moreover, one might argue that it is easier, for the worker, to assess satisfaction with current earnings (by comparing them with what was earned in the past, with earnings in comparable positions and with expectations regarding future earnings, thanks to an underlying variable - i.e., income - that is generally increasing over time) than with work conditions (which are more subject to favourable and unfavourable changes and less easily 
comparable with what is offered by the alternatives). Finally, problems of self-selection may arise, where more optimistic workers may choose to become self-employed.

Table 3 - Maximum Likelihood Multinomial Logit Estimates on Transition Probabilities

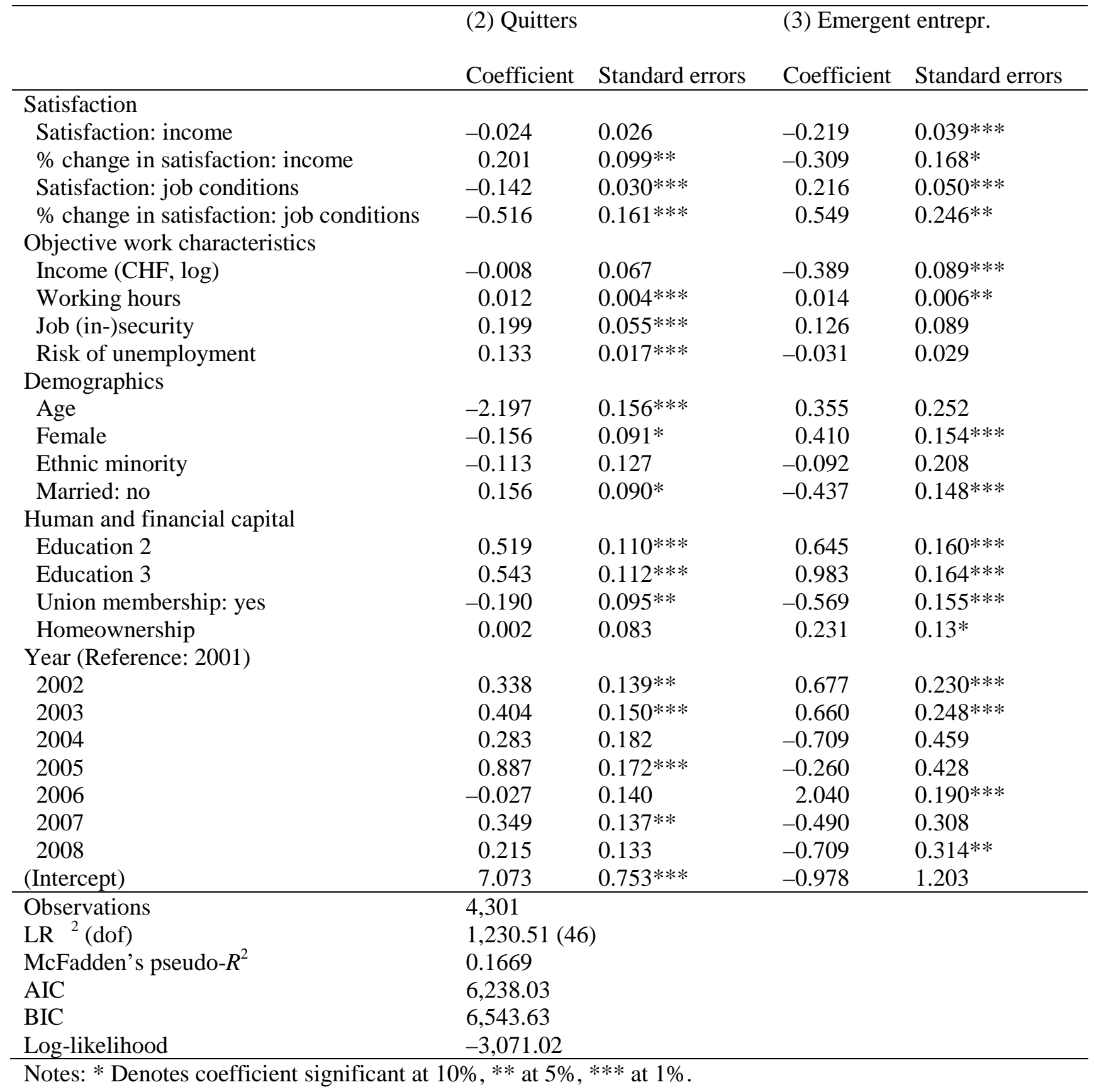

As for the effects of the objective job characteristics, we find a negative effect for the level of (log)income on self-employment probabilities, which implies that higher wages provide a disincentive for transitions into self-employment, while there are no apparent effects on job quits. The number of hours worked is positively and significantly associated to transition probabilities, both for emergent entrepreneurs and for job quitters, suggesting that there is a certain degree of self-selection of the most active/assiduous workers for more 
challenging outcomes. ${ }^{7}$ As for the effects of the other measures of objective working conditions, both the level of self-reported job insecurity and risk of unemployment do not seem to significantly influence transitions to self-employment, but they positively affect job quits.

With regard to our control variables, the probability of quitting appears to be negatively influenced by the age of the respondent, as well as by gender (i.e., males are more likely to quit), whereas the opposite holds for the probability to enter self-employment, although the effect of age is not significant in this case. Nationality does not seem to affect transition probabilities (most likely because of the very few foreigners in our sample), whereas being single or divorced decreases the probability of entering self-employment, because of the inability of singles to draw on the partners' pecuniary and nonpecuniary contributions (which may be crucial, especially in the early times of self-employment), but is positively related to job quits.

Transition probabilities are positively affected by the level of education, suggesting that higher levels of human capital - as expected - increase knowledge regarding the alternatives, whereas unionized workers are more reluctant to change their job/status. Homeownership is seen as a factor positively influencing selfemployment transitions, since it reflects wealth accumulation and because of the fact that housing wealth usually represents a source of collateral for business ownership. Finally, time dummies are mostly significant, reflecting business cycle dynamics.

In order to investigate whether the effect of changes (shocks) to job satisfaction on transition probabilities depend on its starting level, we augment our model by including interaction terms between levels and percentage changes in both satisfaction measures. Table 4 reports our estimates for this specification. The inclusion of interactions slightly improves the goodness of fit (McFadden's pseudo- $R^{2}$ of 0.17 ; AIC 6,223.63 and BIC 6,554.69), and LR tests confirm that this specification is a significant improvement from both the base model (no job satisfaction variables) and the one without interaction terms.

In the new estimates, while size and significance of the coefficients for the level of pecuniary and nonpecuniary satisfaction do not change meaningfully ${ }^{8}$ in both the quitters and the emergent entrepreneurs sample, implying that most of the main effects of long-run satisfaction persist even after controlling for possible interaction effects, the inclusion of interactions moderates the significance of all estimated coefficients for variations in job satisfaction. ${ }^{9}$

However, the non-significant effects found for every interaction term - with the only exception of the quitters' reaction to nonpecuniary satisfaction - suggests that we cannot accept the hypothesis that the longrun level of job satisfaction influences the workers' reaction to recent shocks to the same. As for the significant and negative effect of the interaction term on nonpecuniary satisfaction found for the quitters, according to our results, the effect of a recent decrease in satisfaction will be attenuated for workers with high levels of satisfaction. They already have lower chances of quitting their job (see the negative coefficient

${ }^{7}$ This hypothesis is somehow related to the surprising results found by Taylor (2004) for job satisfaction levels of the self-employed, which report higher levels of job satisfaction with hours of work than employees, despite the welldocumented fact that the former work in general harder than the latter (Blanchflower, 2004).

8 It should be pointed out that, as shown in Balli and Sørensen (2012), the coefficients on the main terms when an interaction term is present, are not directly comparable to the ones obtained in the model without interaction terms. In a model using two independent variables $x_{1}$ and $x_{2}$, the significance test on the regression coefficient for $x_{1}$ is carried out under the hypothesis that $x_{2}=\bar{x}_{2}$, while if $x_{1}$ and $x_{2}$ are interacted, the underlying hypothesis is that $x_{2}=0$.

${ }^{9}$ These results are apparently affected by the choice of the multinomial logit framework, where each effect is estimated by considering deviations from a reference group (i.e., the stayers). Preliminary evidence using a logit model framework (where the benchmark is the joint group of the stayers and quitters), shows that interactions matter. Alternatively, the assumption that the error terms are iid might be relaxed using a nested logit approach (Williams, 1977), which allows for the existence of correlation in a group of alternatives. Furthermore, models that consider more than one random component, allowing for the presence of both correlation and heteroskedasticity (mixed logit), could be explored. 
for the levels), and are less sensitive to shocks. On the other hand, workers who are persistently dissatisfied with their working conditions are more likely to look for a new job and quit, but additional shocks to their level of nonpecuniary job satisfaction appear to moderate the likelihood of quitting, suggesting that the worker may be demoralized by the perceived worsening conditions on the job and may therefore choose to wait, in hopes of regaining confidence, before quitting.

Table 4 - Maximum Likelihood Multinomial Logit Estimates on Transition Probabilities: Model Including Interactions

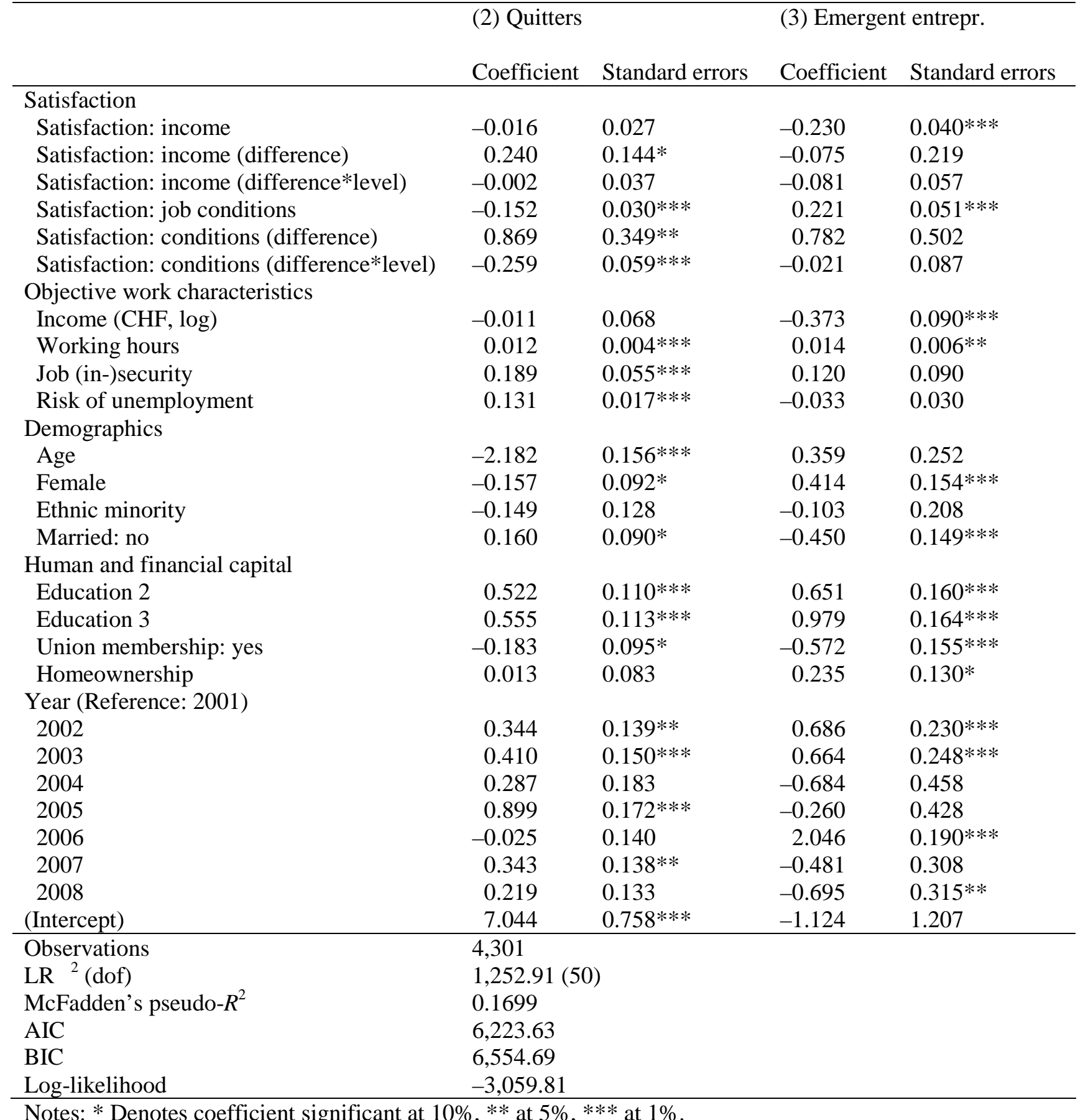

Notes: $*$ Denotes coefficient significant at $10 \%, * *$ at $5 \%, * * *$ at $1 \%$. 


\section{Conclusions}

The recent increase of self-employment in Switzerland (in a trend consistent with the rest of the world) has raised the attention of the academic community and of the public on the effects of small business growth on economic development. The strong belief that small businesses foster innovation and competitiveness has led to a number of policy interventions aiming to encourage start-up activities, although their effects are often disputed. In this framework, it is important to investigate the reasons why individuals choose selfemployment, and why they do it despite lower protection, higher risks, and often more effort than what is offered in a comparable wage employment position.

Using microdata from a panel of Swiss individuals for the years 1999-2008, we investigate the factors that are expected to affect the probability of choosing self-employment (or, alternatively, of just quitting a job for another), given a previous employment position. The availability of panel data allows us to observe the occupational dynamics of each individual, as well as his/her self-assessed satisfaction over pecuniary and nonpecuniary job characteristics, and the actual working conditions, along both dimensions. Such a data setting enables us to condition observed changes in occupational status on the status quo (in terms of satisfaction and working conditions) recorded before the change.

We show that job satisfaction significantly affects transition probabilities towards self-employment or just new jobs. However, its effects are different for the two cases examined. Those who choose self-employment tend to do so in reaction to low levels of pecuniary satisfaction (instead, their level of nonpecuniary satisfaction is higher than the one reported by the reference group of stayers). On the other hand, job quitters are more reactive to nonpecuniary dissatisfaction. Therefore, the distinction between pecuniary and nonpecuniary satisfaction allows us to uncover different effects of subjective job assessments on transition probabilities that a single satisfaction measure would not capture. Variations in job satisfaction are also found to significantly influence transition probabilities, even if their effects are generally absorbed by the interaction terms once we control for threshold effects.

Our study could be expanded in several directions. From a theoretical viewpoint, a microeconomic model describing the relationship between satisfaction (in levels and variations) and occupational choice should ideally be developed to improve the economic identification and interpretation of the effects commented upon in this paper. From a methodological viewpoint, our analysis could be enhanced by considering a specific order or nesting between the occupational choices considered here. Consequently, ordered or nested logit approaches could be tested in further studies, although our diverging results on the effects of pecuniary and nonpecuniary satisfaction on job quitters and emergent entrepreneurs seem to suggest that the two occupational choices should be seen as alternative and motivated by opposite factors (dissatisfaction with working conditions and income, respectively). From an empirical viewpoint, a graphical analysis of the heterogeneous effect of shocks to satisfaction for the model including interaction terms would be desirable. Finally, it would be interesting to test whether the same job quitters and emergent entrepreneurs studied in this paper have actually found better conditions in their new occupation once the choice been made.

Some policy considerations may be attempted, on the basis of our findings. The divergent reactions of the job quitters and emergent entrepreneurs with respect to (time and cross-sectional) differences in pecuniary and nonpecuniary satisfaction suggest that, one the one hand, if they want to reduce turnover managers should pay more attention to employees who are dissatisfied with actual working conditions (since job quitters have been found to be particularly exposed to such issues). Paying more attention to the employees' personal needs, offering flexibility and social interaction opportunites, are some of the measures that could be considered. On the other hand, if their aim is to reduce the risks of future competition managers should care about pecuniarily dissatisfied workers, given their higher probability of switching to self-employment. In this case, specific incentives and bonus structures, along with a challenging position, could be well suited. 
Moreover, it is likely that, given the dominance of levels over variations in job satisfaction, workers will tend to absorb temporary shocks in job satisfaction without changing their perception about the available alternatives. Therefore, more attention is needed for those individuals that show persistently low satisfaction levels.

Finally, considering our results, it might be worth asking ourselves why an individual (an emergent entrepreneur) would express a different level of satisfaction over income than another individual receiving the same income. It seems reasonable to assume that self-employment candidates are somehow 'predestined' to start a business. Indeed, in their preceding job they are among the most active workers and they are generally less sensitive with respect to working conditions. This process of (self-)selection of less satisfied workers into more suitable jobs is expected to favour the job matching process, allowing for a more effective match between the needs of the workers and of businesses. Moreover, the competition generated by employees-turned-entrepreneurs, if in the same business field, may foster growth and economic development. Therefore, from a general perspective, these choices - though they often reflect objective and/or subjective problems - should be favoured rather than detered. Facilitating them (e.g., by means of specific start-up programs, youth employment measures, micro- and facilitated credit) could give rise to efficiency and productivity gains in the labour market, thanks to an improved distribution of skills and aspirations between employees and independent workers.

\section{Acknowledgments}

The first author wishes to thank Rico Maggi for his generous assistance and his motivational impulses that led this paper to participate to the NARSC Student Paper Competition. The authors are grateful to John T. Addison (University of South Carolina), as well as to participants to the 58th Annual North American Meetings of the Regional Science Association International (Miami, FL), the Tinbergen Institute Workshop (Amsterdam) and a seminar at the University of Oviedo (Oviedo), for useful comments on the paper.

\section{References}

Acs Z and Armington C (2004) Employment Growth and Entrepreneurial Activity in Cities. Regional Studies 38: 911-927.

Akerlof GA, Rose AK, Yellen JL, et al. (1988) Job Switching and Job Satisfaction in the U.S. Labor Market. Brookings Papers on Economic Activity 1988: 495-594.

Balli HO and Sørensen BE (2012) Interaction Effects in Econometrics. Empirical Economics (forthcoming).

Bartel AP and Borjas GJ (1981) Wage Growth and Job Turnover: An Empirical Analysis. In: Rosen S (ed)

Studies in labor markets. Chicago London: The University of Chicago Press, 65-90.

Birch DL (1979) The Job Generation Process, Cambridge: M.I.T. Program on Neighborhood and Regional Change.

Birchmeier U (2000) L'essor de l'emploi indépendant en Suisse. La Vie économique 10: 52-56.

Black J, Meza Dd and Jeffreys D (1996) House Prices, The Supply of Collateral and the Enterprise Economy. The Economic Journal 106: 60-75.

Blanchflower DG (2000) Self-Employment in OECD Countries. Labour Economics 7: 471-505.

Blanchflower DG (2004) Self-Employment: More May not Be Better. Swedish Economic Policy Review 11: 15-74.

Blanchflower DG and Freeman RB (1997) The Attitudinal Legacy of Communist Labor Relations. Industrial and Labor Relations Review 50: 438-459.

Blanchflower DG and Oswald AJ (1998) What Makes an Entrepreneur? Journal of Labor Economics 16: 2660. 
Blau DM (1985) Self-Employment and Self-Selection in Developing Country Labor Markets. Southern Economic Journal 52: 351-363.

Brock WA, Evans DS and Phillips BD (1986) The Economics of Small Businesses: Their Role and Regulation in the U.S. Economy, New York: Holmes \& Meier.

Brockhaus RH (1982) The Psychology of the Entrepreneur. In: Kent CA, Sexton DL and Vesper KH (eds) Encyclopedia of entrepreneurship. Englewood Cliffs: Prentice-Hall, Inc., 39-56.

Clark A, Georgellis Y and Sanfey P (1999) Job Satisfaction, Wage Changes and Quits: Evidence from Germany. Research in Labor Economics 17: 95-121.

Clark AE (2001) What Really Matters in a Job? Hedonic Measurement Using Quit Data. Labour Economics 8: $223-242$.

Clark AE and Oswald AJ (1996) Satisfaction and Comparison Income. Journal of Public Economics 61: 359-381.

Dunne T, Roberts M and Samuelson L (1987) The Impact of Plant Failure on Employment Growth in the US Manufacturing Sector. University Park: Pennsylvania State University.

Evans DS (1987a) The Relationship Between Firm Growth, Size, and Age: Estimates for 100 Manufacturing Industries. The Journal of Industrial Economics 35: 567-581.

Evans DS (1987b) Tests of Alternative Theories of Firm Growth. Journal of Political Economy 95: 657-674.

Evans DS and Jovanovic B (1989) An Estimated Model of Entrepreneurial Choice under Liquidity Constraints. Journal of Political Economy 97: 808-827.

Evans DS and Leighton LS (1989) Some Empirical Aspects of Entrepreneurship. The American Economic Review 79: 519-535.

Evans DS and Leighton LS (1990) Small Business Formation by Unemployed and Employed Workers. Small Business Economics 2: 319-330.

Falter J-M (2001) Self-Employment Entry and Duration in Switzerland. Geneva: University of Geneva.

Falter J-M, Ferro-Luzzi G and Flückiger Y (1998) Travail à temps partiel et indépendants en Suisse: éléments d'explication de l'évolution récente. Sécurité sociale 3.

Flanagan RJ, Strauss G and Ulman L (1974) Worker Discontent and Work Place Behavior. Industrial Relations: A Journal of Economy and Society 13: 101-123.

Flückiger Y and Ferro-Luzzi G (2001) Le travail indépendant en Suisse. Bern: Demain la Suisse.

Freeman RB (1978) Job Satisfaction as an Economic Variable. The American Economic Review 68: 135-141. FSO (2000) Federal Population Census. Neuchâtel: FSO.

FSO (2011a) Statistical Yearbook 2011, Zurich: Verlag Neue Zürcher Zeitung.

FSO (2011b) Statistisches Jahrbuch der Schweiz 2011 - Digital. CD-Rom.

Fujii ET and Hawley CB (1991) Empirical Aspects of Self-Employment. Economics Letters 36: 323-329.

Goetz SJ, Fleming DA and Rupasingha A (2012) The Economic Impacts of Self-Employment. Journal of Agricultural and Applied Economics 44: 315-321.

Gottschalk P and Maloney T (1985) Involuntary Terminations, Unemployment, and Job Matching: A Test of Job Search Theory. Journal of Labor Economics 3: 109-123.

Greene WH (2007) Econometric Analysis, Upper Saddle River: Prentice-Hall.

Guerra G, Patuelli R and Maggi R (2012) Ethnic Concentration, Cultural Identity and Immigrant SelfEmployment in Switzerland. In: Nijkamp P, Poot J and Sahin M (eds) Migration Impact Assessment: New Horizons. Cheltenham Northampton (forthcoming): Edward Elgar.

Hamilton Barton H (2000) Does Entrepreneurship Pay? An Empirical Analysis of the Returns to Self - Employment. Journal of Political Economy 108: 604-631.

Henley A (2005) Job Creation by the Self-employed: The Roles of Entrepreneurial and Financial Capital. Small Business Economics 25: 175-196.

Hofstede G, Noorderhaven NG, Thurik AR, et al. (2004) Culture's Role in Entrepreneurship: SelfEmployment out of Dissatisfaction. In: Brown TE and Ulijn J (eds) Innovation, Entrepreneurship and Culture: The Interaction between Technology, Progress and Economic Growth. Cheltenham Northampton: Edward Elgar Publishing, 162-203.

Holtz-Eakin D, Joulfaian D and Rosen HS (1994) Entrepreneurial Decisions and Liquidity Constraints. The RAND Journal of Economics 25: 334-347.

Jovanovic B (1982) Selection and the Evolution of Industry. Econometrica 50: 649-670.

Kihlstrom RE and Laffont J-J (1979) A General Equilibrium Entrepreneurial Theory of Firm Formation Based on Risk Aversion. Journal of Political Economy 87: 719-748. 
Lazear EP and Moore RL (1984) Incentives, Productivity, and Labor Contracts. The Quarterly Journal of Economics 99: 275-296.

Lévy-Garboua L, Montmarquette C and Simonnet V (2007) Job Satisfaction and Quits. Labour Economics 14: 251-268.

Lindh T and Ohlsson H (1996) Self-Employment and Windfall Gains: Evidence from the Swedish Lottery. The Economic Journal 106: 1515-1526.

Lucas RE, Jr. (1978) On the Size Distribution of Business Firms. The Bell Journal of Economics 9: 508-523.

McEvoy GM and Cascio WF (1985) Strategies for Reducing Employee Turnover: A Meta-Analysis. Journal of Applied Psychology 70: 342-353.

McFadden D (1974) Conditional Logit Analysis of Qualitative Choice Behavior. In: Zarembka P (ed) Frontiers in Econometrics. New York: Academic Press, 105-142.

Noorderhaven N, Thurik R, Wennekers S, et al. (2004) The Role of Dissatisfaction and per Capita Income in Explaining Self-Employment across 15 European Countries. Entrepreneurship Theory and Practice 28: 447-466.

Pakes A and Ericson R (1998) Empirical Implications of Alternative Models of Firm Dynamics. Journal of Economic Theory 79: 1-45.

Rees H and Shah A (1986) An Empirical Analysis of Self-Employment in the U.K. Journal of Applied Econometrics 1: 95-108.

Reynolds P (1994) Autonomous Firm Dynamics and Economic Growth in the United States, 1986-1990. Regional Studies 28: 429-442.

Reynolds PD (1999) Creative Destruction: Source or Symptom of Economic Growth? In: Acs ZJ, Carlsson B and Karlsson C (eds) Entrepreneurship, Small \& Medium-Sized Enterprises and the Macroeconomy. Cambridge New York Melbourne: Cambridge University Press, 97-136.

Rosen S (1981) The Economics of Superstars. The American Economic Review 71: 845-858.

Shapero A and Sokol L (1982) The Social Dimensions of Entrepreneurship. In: Kent CA, Sexton DL and Vesper KH (eds) Encyclopedia of entrepreneurship. Englewood Cliffs: Prentice-Hall, Inc., 72-90.

Taylor M (2004) Self-Employment in Britain: When, Who and Why? Swedish Economic Policy Review 11: 139-173.

Taylor MP (1996) Earnings, Independence or Unemployment: Why Become Self-Employed? Oxford Bulletin of Economics and Statistics 58: 253-266.

Wennekers S, Noorderhaven N, Hofstede G, et al. (2001) Cultural and Economic Determinants of Business Ownership across Countries. In: Bygrave WD, Autio E, Brush CG, et al. (eds) Frontiers of Entrepreneurship Research 2001: Proceedings of the Twenty-First Annual Entrepreneurship Research Conference. Babson Park: Center for Entrepreneurial Studies, Babson College, 179-190.

Williams HCWL (1977) On the Formation of Travel Demand Models and Economic Evaluation Measures of User Benefit. Environment and Planning A 9: 285-344. 


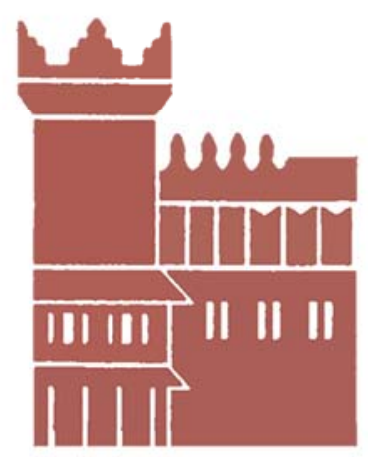

Alma Mater Studiorum - Università di Bologna DEPARTMENT OF ECONOMICS

Strada Maggiore 45

40125 Bologna - Italy

Tel. +39051 2092604

Fax +390512092664

http://www.dse.unibo.it 